\title{
A Substrate Serves as a Hydrogen Atom Donor in the Enzyme-Initiated Catalytic Mechanism of Dual Positional Specific Maize Lipoxygenase-1
}

\author{
Thav ralk Huon, Sungluk Jang, Kyoungwon Cho, Randeep Rakwal,; Je Chang Woo, ${ }^{\ddagger}$ \\ Ilchul Kim, ${ }^{\text {\$ Seung-Wook Chi,", and Oksoo Han }}$
}

\author{
Department of Molecular Biotechnologv, BK2I Globalization of Biotechnologv Human Resources, \\ Biotechnologv Research Institute, College of Agriculture and Life Sciences, Chonnam National Chiversin. \\ Gwangit 500-757, Korea. 'E-mail: oshan achonnam.ack \\ Health Technologv Research Center (HTRC), National Institute of Advanced Industrial Science and Technologv (AIST), \\ Tsuthtiba 305-8569, Ibaraki, Japan \\ ${ }^{\ddagger}$ Department of Biotechnologv, College of Natural Sciences, Hokpo Kational University, Hokpo 534-729, Korea \\ SDepartment of Biological Sciences, College of Natural Sciences. Chonnam National Chiversin. Gu'angiu 500-757, Korea \\ "Medical Proteomics Research Center, KRIBB, Daejeon 305-806, Korea \\ Received December 17, 2008. Accepted February 23, 2009
}

\begin{abstract}
The maize lipoxgyenase-l is a non-traditional dual positional specific enzyme and the reaction proceeds via enzyme-initiated catalysis. Bioinformatic analysis indicated that the maize lipoxygenase-l is structurally more similar to soybean LOX1 than pea LOXN2 in that it has an additional external loop (residues 318-351) in the carboxy-temininal catalytic domain. We analyzed the dependence of product distribution on concentration of linoleic acid and monitored the fonnation of hydroperoxyoctadecadienoic acid as a function of enzyme concentration. Product distribution was strongly influenced by substrate concentration, such that kinetically-controlled regioisomers were enriched and thenmodymanically-controlled regioisomers were depleted at high substrate concentration. Kinetic studies indicated that the fomation of hydroperoxyoctadecadienoic acid saturated rapidly in an enzyme concentration-dependent manner, which implied that reactivation by reoxidation of inactive $\mathrm{Fe}(\mathrm{II})$ failed to occur. Our results support the previously proposed enzyme-initiated catalytic mechanism of the maize lipoxgyenase-l and reveals that a substrate molecule serves as a hydrogen atom donor in its enzyme-initiated catalysis.
\end{abstract}

Key Wonds: Dual positional lipoxygenase, Enzyme-initiated mechanism. Kinetic control, Thermodynamic control. Radical mechanism

\section{Introduction}

Lipoxygenases (LOXs) (EC 1.13.14.12) are iron- or manganese-containing dioxygenases. which are ubiquitous in animals and plants. ${ }^{1.2}$ In the presence of molecular oxygen. LOXs catalyze the hydroperoxidation of polyunsaturated fatty acids with one or more (IZ.4Z)-pentadienes. Theoretically. four regioisomers can be produced with linoleic acid (LA) as a substrate if the W-conformation of the substrate is maintained throughout the reaction (Figure 1). These regioisomers can be divided into two groups: $(9 Z, 11 \mathrm{E})$-13-hydroperoxy-9.11-octadecadienoic acid (13-(9Z.11E)HPODE) and (10E,12Z)-9-hydroperoxy-10,12-octadecadienoic acid (9-(10E. 12Z)HPODE) are cis/trans isomers and are considered kinetically-controlled products; and (9E,11E)-13-hydroperoxy-9,11octadecadienoic acid (13-(9E. 11E)HPODE) and (10E 12E)9-hydroperoxy-10.12-octadecadienoic acid (9-(10E.12E)HP$\mathrm{ODE}$ ) are trans/trans isomers and are thermody namicallycontrolled products. ${ }^{3}$ Most LOX-catalyzed reactions are regioselective and stereoselective. and produce primarily kinetically-controlled products. For example. LA and linolenic acid (LNA) are oxygenated at C-9 or C-13 of the hydrocarbon backbone of the unsaturated fatty acid. and $9(\mathrm{~S})-(10 \mathrm{E}, 12 \mathrm{Z})$ lydroperoxyoctadecadienoic (trienoic) acid (HPOD(T)E) or $13(\mathrm{~S})$-(9Z.11E)HPOD(T)E are produced by 9 -LOX or 13-LOX, respectively: ${ }^{\text {A.S }}$
A few naturally-occurring plant LOXs exhibit dual positional specificity: these enzymes are classified as non-traditional LOXs. because their patterns of regio- and stereoselectivity are distinct from traditional LOX enzymes. ${ }^{6.9}$ Wound-inducible maize LOXI is a non-traditional LOX with dual positional specificity, ${ }^{6,10.11}$ whose pre-steady state kinetic behavior has been characterized. ${ }^{12}$ Although the regioselectivity and stereoselectivity of traditional LOX enzy mes have been characterized extensively. ${ }^{13}$ the catalytic mechanism of non-traditional dual positional specific LOX enzymes remains controversial. ${ }^{1+}$ We recently demonstrated that maize LOX1 produced not only kinetically-controlled $(\mathrm{KC})$ products but also thermodynamically-controlled (TC) products. and provided regiochemical/stereochemical evidence that maize LOX1 acts by a unique enzyme-initiated catalytic mechanism. ${ }^{15}$ This study compares properties of the maize LOXI with other non-traditional LOXs. examines the dependence of product distribution on the concentrations of LA, and effect of enzyme concentration on reaction kinetics (i.e. rate of formation of HPODE). The results support the previously proposed enzyme-initiated catalytic mechanism, and reveal that substrate concentration is a critical deterninant of product distribution. A possible chemical mechanism for the formation of thermody'namically- and kinetically-controlled products during enzyme-initiated cataly sis by maize LOX1 is discussed. 


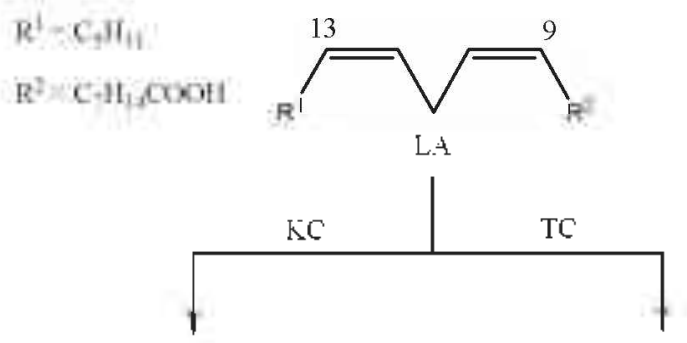

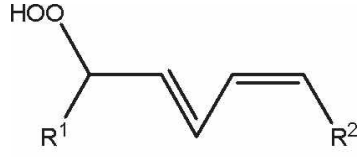

13-(9Z,11E)HPODE

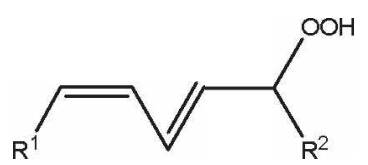

9-(10E.12Z)HPODE

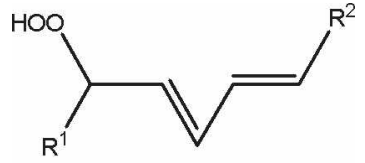

13-(9E, 11E)HPODE

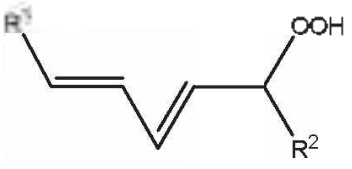

9-( $10 \mathrm{E}, 12 \mathrm{E}) \mathrm{HPODE}$
Figure 1. Fommation of kinetically-controlled and thenmodynamically-controlled products during non-traditional LOX reaction with LA as a substrate.

\section{Experimental Section}

Potein purification, separation, and stmictural identification of regioisomers. The $\mathrm{pRSETB} / \mathrm{LOX}$ vector ${ }^{6.15}$ was transfonned into BL2 (DE3)pLys $\$$. which was grown in 50 $\mathrm{mL}$ of LB containing $50 \mu \mathrm{g} / \mathrm{mL}$ ampicillin and $35 \mu \mathrm{g} / \mathrm{mL}$ chloramphenicol at $37^{\circ} \mathrm{C}$ until the cell density reached to $\mathrm{OD}_{\sigma(\omega)}=0.6$, and further cultured at $25^{\circ} \mathrm{C}$ for $12 \mathrm{hr}$ after addition of isopropy $\beta-D-1$-thiogalactopyranoside (IPTG) at a final concentration of $1 \mathrm{mM}$. Bacterial cells were harvested by centrifugation $\left(3000 \mathrm{Ng} .15 \mathrm{~min} .4^{\circ} \mathrm{C}\right)$. briefly washed with $50 \mathrm{mM}$ Tris- $\mathrm{HCl}$ (pH 7.2). and resuspended in $3 \mathrm{~mL}$ of $50 \mathrm{mM}$ Tris- $\mathrm{HCl}(\mathrm{pH} 7.2), 0.1 \%$ Tween $20(\mathrm{v} / \mathrm{v})$ and $0.2 \mathrm{mM}$ phenylmethylsulphonyl fluoride (PMSF). The resuspended cells were disnupted by sonication and cell debris was removed by centrifugation $\left(13,000 \mathrm{rg} .1 \mathrm{hr},{ }^{\circ} \mathrm{C}\right)$. Soluble fraction ( $1 \mathrm{~mL}$ ) of the maize LOXl was loaded on a $2 \mathrm{~mL}$ of Q-sepharose resin column pre-equilibrated with $50 \mathrm{mM}$ Tris- $\mathrm{HCl}(\mathrm{pH} 7.2$ ). The column was washed with $10 \mathrm{~mL}$ of 50 $\mathrm{mM}$ Tris- $\mathrm{HCl}(\mathrm{pH} 7.2)$. The maize LOXI was eluted with 5 $\mathrm{mL}$ of $50 \mathrm{mM} \mathrm{NaCl}$ in $50 \mathrm{mM}$ Tris- $\mathrm{HCl}$ (pH 7.2) by gravity flow. The homogeneity of purified maize LOX was confinned by SDS-PAGE.

Enzymatic reaction and stnctural identification of enzymatic products. Enzymatic reaction and reduction with triphenylphosphine (TPP) was carried out according to a previously described procedure. ${ }^{13.15}$ For $\mathrm{NaBH}_{4}$-reduction ${ }^{6}$ method. purified maize LOXl (72 $\mu \mathrm{g})$ was incubated in $50 \mathrm{mM}$ Tris- $\mathrm{HCl}$ ( $\mathrm{pH} \mathrm{7.2)} \mathrm{containing} 0.5 \mathrm{mM} \mathrm{LA}, 0.05 \%$ Tween 20 $(\mathrm{F} / \mathrm{v})$ for $15 \mathrm{~min}$ at room temperature in a final volume of 2.5 $\mathrm{mL}$. The reaction was stopped by addition of $\mathrm{NaBH}_{4}$. HPODEs were reduced by $\mathrm{NaBH}_{4}$ for $15 \mathrm{~min}$ at $25^{\circ} \mathrm{C}$. The $\mathrm{pH}$ was adjusted to 3 by addition of $1 \mathrm{~N} \mathrm{HCl}$. The reaction nuxture was immediately loaded on a Sep-pak $C_{1}$ solid-phase extraction cartridge pre-washed and pre-equilibrated with distilled water. Reaction product and un-reacted substrate were retained by the cartridge. which was washed with $10 \mathrm{~mL}$ of $10 \%$ methanol $(\mathrm{v} / \mathrm{v})$ in water and $10 \mathrm{~mL}$ distilled water. Excess water was removed from the cartridge with a syringe and the adsorbed components were eluted with $3 \mathrm{~nL}$ dry 2-propanol.

The solvent was evaporated and positional isomers of oxygenated fatty acids were separated by SP-HPLC as described previously. ${ }^{15}$ The mixture of HODEs was loaded on a Mightysil Si 60 colunn $(250 \times 4.6 \mathrm{~nm}, 5 \mu \mathrm{m}$ particle size $)$ from Kanto Chemical (Tokyo. Japan) and eluted with isocratic solvent system of $n$-hexane/2-propanol/acetic acid $(100 / 2 / 0.1 \mathrm{v} / \mathrm{v} / \mathrm{v})$ with a flow rate of $1.0 \mathrm{~mL} / \mathrm{nun}$. Absorbances at $234 \mathrm{~nm}$ and $210 \mathrm{~nm}$ were recorded simultaneously: Solvent was evaporated and separated positional isomers were subjected to NMR and GC-MS analy sis. ${ }^{6.15}$ For GC-MS analysis. each HODE separated by SP-HPLC was derivatized with $10 \mu \mathrm{L}$ of SIGMA-SIL-A at $80^{\circ} \mathrm{C}$ for $5 \mathrm{~min}$. Trimethy lsilylated HODE ( $1 \mu \mathrm{L}$ ) was loaded onto HP-5MS (30 $\mathrm{m} \times$ $0.25 \mathrm{~mm}$ : $0.25 \mu \mathrm{m}$ film thickness). Injector and detector temperatures were set at $260^{\circ} \mathrm{C}$ and $300^{\circ} \mathrm{C}$. respectively. The temperature program was $100^{\circ} \mathrm{C}$ (hold for $1 \mathrm{~min}$ ) to $160^{\circ} \mathrm{C}$ at $20^{\circ} \mathrm{C} / \mathrm{min}$ and $4^{\circ} \mathrm{C} / \mathrm{min}$ to $280^{\circ} \mathrm{C}$ (hold for $4 \mathrm{~min}$ ).

Dependence of product distribution on substrate concentration and quantification of HPODE. Maize LOX1 (72 or 1.0 $\mu g)$ was incubated in $50 \mathrm{mM}$ Tris- $\mathrm{HCl}(\mathrm{pH}$ 7.2) containing $0.05 \%$ Tween $20(\mathrm{v} / \mathrm{v})$ and various concentrations of LA $(0.03,0.04,0.05 .0 .1$ and $0.5 \mathrm{mM})$ at room temperature for 15 min in a final volume of $2.5 \mathrm{~mL}$. The reaction was stopped by addition of chilled-methanol/acetic acid and products were extracted with Sep-pak $C_{18}$ solid-phase extraction cartridge. Reaction products were reduced with TPP. and analyzed by SP-HPLC. Production of HPODE was quantified in standard LOX assays containing $0.4,0.7,1.8,3.5,4.9,6.0$ or $7.0 \mu \mathrm{g}$ maize LOXI. Standard assay conditions included $0.5 \mathrm{mM}$ LA. $0.05 \%$ Tween $20(\mathrm{v} / \mathrm{v})$ and $50 \mathrm{mM}$ Tris- $\mathrm{HCl}(\mathrm{pH} 7.2)$ in a final volume of $2.5 \mathrm{~mL}$, with incubation at $25^{\circ} \mathrm{C}$ for $15 \mathrm{~min}$. Reactions were monitored spectrophotometrically at $234 \mathrm{~nm}$.

\section{Results}

Sequence analysis and structural mokeling of maize LOX1. The regio- and stereochemical characteristics of non-traditional plant LOXs. including maize LOX1, are summarized in Table 1. Most non-traditional LOXs show dual positional specificity and loose stereoselectivity. For example, maize LOXI produces a 1: 1 mixture of enantiomers at both C-9 and C-13 and is only example of completely non-stereoselective dual positional specific LOX in monocots. Anino acid sequence comparison showed that maize LOXI shared a high degree of homology among LOX enzymes from monocot species. The regio- and stereoselectivity of maize LOXI were similar to those of soybean LOX3 and pea LOXs. Figure 2 shows a protein sequence alignment of maize LOX1, pea LOXN2, and soybean LOX3. The alignment indicates strong 
Table 1. Regioselectivity and stereoselectivity of non-traditional plant LOXs

\begin{tabular}{|c|c|c|c|c|c|c|c|c|c|}
\hline \multirow{3}{*}{\multicolumn{2}{|c|}{ Species }} & \multirow{3}{*}{ Enzyme } & \multirow{3}{*}{ Protein ID } & \multirow{3}{*}{$\begin{array}{l}\text { Homology with } \\
\text { LOX } 1-\angle m l(\%)\end{array}$} & \multirow{2}{*}{\multicolumn{2}{|c|}{$\begin{array}{l}\text { P'utative amino } \\
\text { acid deteminant }\end{array}$}} & \multicolumn{3}{|c|}{ Specificity } \\
\hline & & & & & & & \multirow{2}{*}{$\begin{array}{c}\text { Regio } \\
13: 9\end{array}$} & \multicolumn{2}{|c|}{ Stereo } \\
\hline & & & & & Regio & Stereo & & $13(\mathrm{~S}: \mathrm{R})$ & $9(S: R)$ \\
\hline \multirow{4}{*}{ Monocot } & Maize & LOXI-ZnI & AAF76207 & 100 & TV:R & A & $60: 40^{a}$ & $50: 50$ & $50: 50$ \\
\hline & & LOXI-Osl & $\mathrm{CAA}+5738$ & 86 & TVR & A & $89: 11^{t h}$ & $91: 9$ & $50: 50$ \\
\hline & Rice & OsLOX1 & $\mathrm{ABD} 47523$ & 79 & TV:R & A & $57: 43^{c}$ & $S$ & $\mathrm{~S}$ \\
\hline & Barley & $\mathrm{LOX} 1-\mathrm{H} \times 3$ & $\mathrm{AAB} 70865$ & 84 & TV:K & A & $88: 12^{d}$ & $78: 22$ & $80: 20$ \\
\hline \multirow{6}{*}{ Dicot } & Potato & LOX1-St2 & $\mathrm{CAB} 65460$ & 72 & TV: $\mathrm{R}$ & A & $50: 50^{\circ}$ & NA & NA \\
\hline & Cucumber & $\mathrm{LOXl}-\mathrm{Cs} 3$ & CAAG3+83 & 71 & TH R & A & $84: 16^{\prime}$ & $97: 3$ & $89: 11$ \\
\hline & Pea & LOX1-Ps 3 & CAA55319 & 70 & TF:R & A & $33: 67^{8}$ & NA & NA \\
\hline & Pea & LOX1-Ps2 & CAA55318 & 69 & $\mathrm{SF} \mathrm{R}$ & A & $80: 20^{\circ}$ & NA & NA \\
\hline & Pea & LOXN2 & $\mathrm{CAG}+4502$ & 65 & TY R & A & $25: 75^{4}$ & NA & NA \\
\hline & Soybean & LOX3 & CAA 30016 & 70 & TF:R & A & $38: 62^{\prime}$ & $50: 50$ & $50: 50$ \\
\hline
\end{tabular}

$a^{6.15} \cdot b^{18} \cdot c^{19} \cdot d^{9} \cdot e^{2} \cdot f^{\wedge 0} \cdot g^{\hat{1}} \cdot h^{16} \cdot t^{\wedge 9} \cdot$ NA: Not available.

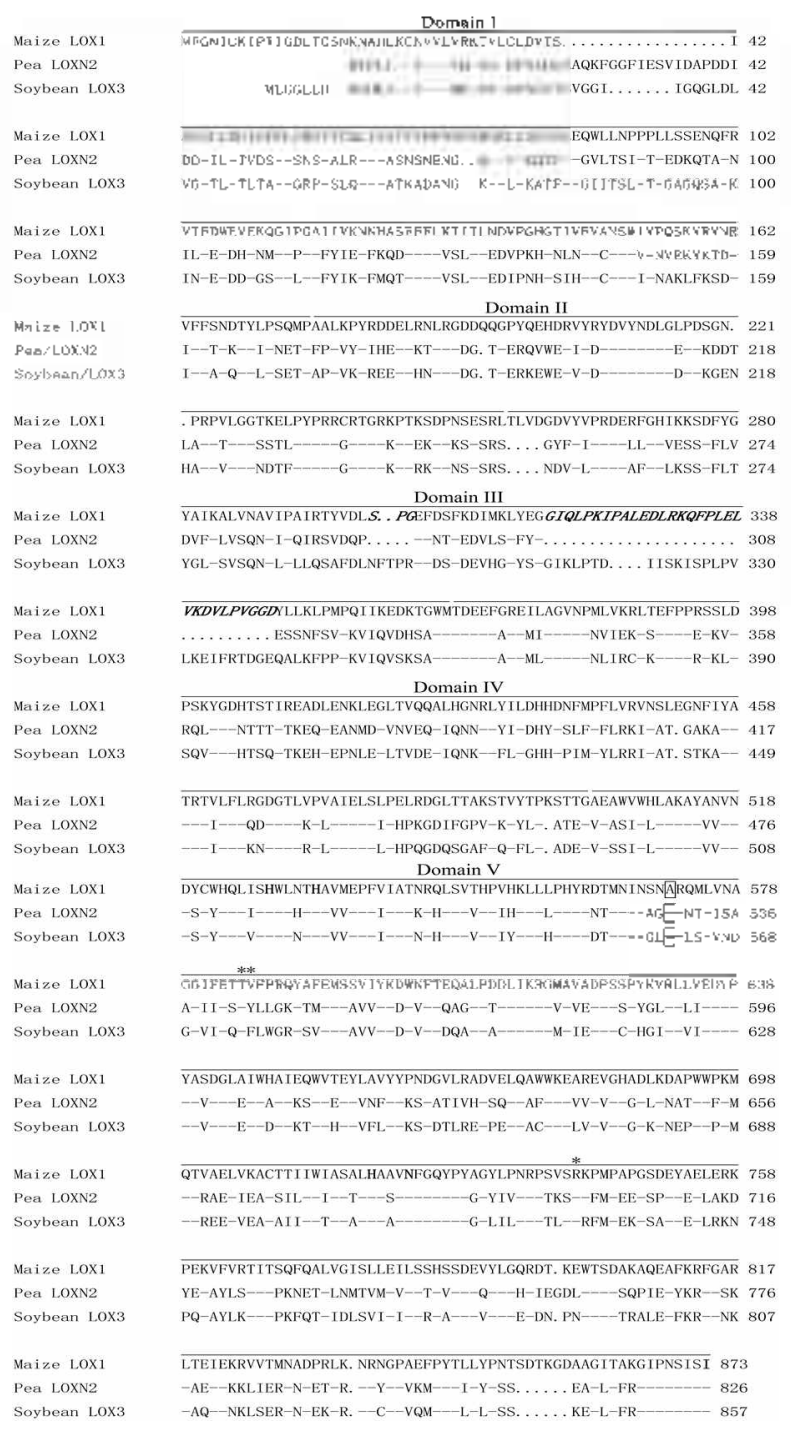

Figure 2. Amino acid sequence alignment of maize LOX1, pea LOXN2, and soybean LOX3. The sequence alignment was performed using CLUSTAL W (v.1.83). Identical residnes are indicated by a hyphen $(-)$. Dots $(\cdot)$ indicate gaps introduced to maximize the alignment. Bold letters indicate residnes involved in iron binding. Asterisks and boxes indicate motifs in traditional LOXs that are responsible for positional specificity and stereoselectivity; respectively. Bold italics represent the external loop region of domain III (deleted in pea LOXN2). Domains are indicated by lined on the MzLOX amino acid sequence. conservation of residues involved in iron binding ${ }^{16}$ as well as motifs found in traditional LOXs that play roles in positional selectivity and stereoselectivity', so called "Coffa site"."

Upon sequence comparison, maize LOXl (Genbank accession No. AF271894) showed 52\% identity and 69\% similarity to soybean LOX1 (Genbank accession No. J02795) and $49 \%$ identity and $65 \%$ similarity to pea LOXN2 (EMBL accession No. AJ749702). The homology modeled structures of maize LOX1 and pea LOXN2 were obtained by program Swiss-Model using the structural template of soybean LOXI (PDB code: $1 F 8 \mathrm{~N}$ ). For comparison the modeled structure of the maize LOXI was superimposed with crystal structure of soybean $\mathrm{LOXl}^{\text {si }}$ and the homology modeled structure of pea LOXN2. ${ }^{16}$ Results are shown in Figure 3A. The residues 1-20 are missing in the modeled maize LOXl stnucture because the corresponding region is absent in the structural template. The Ramachandran plots drawn by the program PROCHECK ${ }^{2-4}$ showed that $85.3 \%$ of all the residues fall within the most favored regions. $12.9 \%$ in additional allowed regions, $1.2 \%$ in generously allowed regions, and $0.5 \%$ in disallowed regions. As seen in Figure 3A. the naize LOX1 consists of two discrete functional domains. amino-terminal $\beta$-barrel PLAT domain (colored cyan in the upper part) and the carboxyterminal catalytic domain (colored blue in the lower part). The overall structures of the three LOX enz'mes are very similar. The structure of maize LOXl is more sinular to that of soybean LOXI than that of pea LOXN2 in that it has an additional external loop (residues 318-351) in the carboxyteminal catalytic domain. which is consistent with regiochemical and stereochemical outcome seen in Table 1. The superimposition with structure of soybean $L O X 1$ also reveals five inserted loops in the structure of maize LOXI. The inserted loops include residues $35-49.140-143$ in domain I, 254-257 in domain II. 324-327 in domain III. and 855-860 in domain $\mathrm{V}$. The most noticeable difference between maize LOXI and the other LOXs is its amino-terminal extension. One of the resulting extra loops may be an external loop composed of residues $35-49$ in the donain I. The loop is likely to very flexible as observed in the structure of soybean LOXI. Upon insertion of the five external loops, both the $\beta$-barrel domain and the catalytic site undergo no appreciable conformational change. The iron binding residues (His 28. His 533. His719. Asn723. and Ile873) also remain in the same positions in domain V. Figure $3 \mathrm{~B}$ shows electrostatic potential 
A
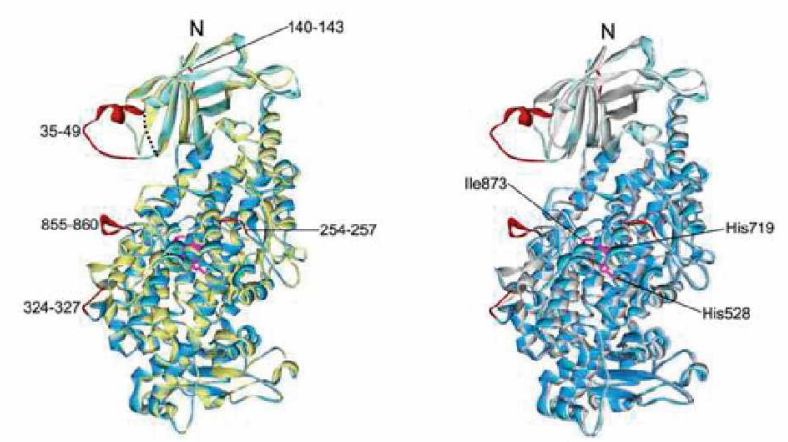

B

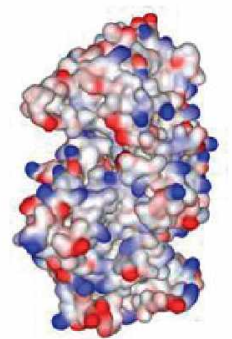

Maize LOX1

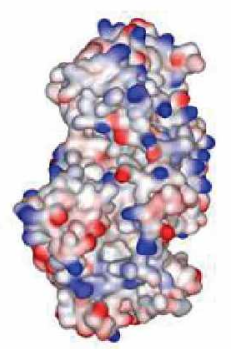

Soybean LOX1

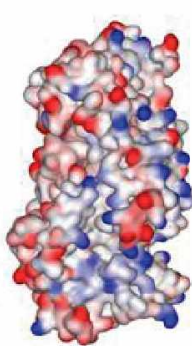

Pea LOXN2

Figure 3. Structural comparison of the maize LOXl with soybean LOXI and pea LOXN2. (A) The superimposition of the modeled maize LOXI structure (blue and cyan) with structures of soy bean LOXI (yellow in the left panel) and pea LOXN2 (gray in the right panel). The amino-terminal $\beta$-barrel PLAT domain and the carboxv-terminal catalytic domain are colored cyan and blue, respectively. The regions that are present in maize LOX1 but absent in soybean LOX1 or pea LOXN2 are colored red and iron binding residues are colored pink. The $\mathrm{N}$-temini are labeled with capital letter N. Dotted lines indicate the absence of crystal structure in sovbean LOXI due to little electron density. ${ }^{23}$ The homology modeled structure of pea LOXN2 contains residues 43-826. (B) Electrostatic potential distribution of the three LOX enzymes. The molecular surfaces with electrostatic potential were generated by the Discovery Studio software (Accelrys). Positive and negative potentials are colored blue and red, respectively. The molecular orientation is the same as in (A).

distribution of the molecular surface of three LOX enzy'mes. Although the overall electrostatic potential distribution is similar, pea LOXN2 shows relatively more negativelycharged surface than maize LOXI and soybean LOXI. Like overall structure, the electrostatic potential distribution of maize LOXI is more similar to that of soybean LOXI than that of pea LOXN2. Such subtle difference in surface charge of the catalytic domain may influence the substrate orientation potentially leading to distinction in positional specificity and stereoselectivity of LOX enzymes.

Enzyme purification and metal analysis. Recombinant maize LOX1 (free of epitope or affinity tag) was expressed in E. coll from the pRSETB:LOX plasmid and soluble protein was purified to homogeneity by Q-Sepharose chromatography as described previously. ${ }^{15}$ Metal analysis was conducted by inductively coupled plasma (ICP). Purified maize LOXI (3.5 mg: 7.6 runole) contained $0.36-0.40 \mu \mathrm{g}$ iron (6.8-7.2 nunole). Therefore the maize LOX1 is a non-heme iron-containing LOX with one iron atom per enzyme molecule.

UV-visible spectral analysis of the maize LOX1 catalytic

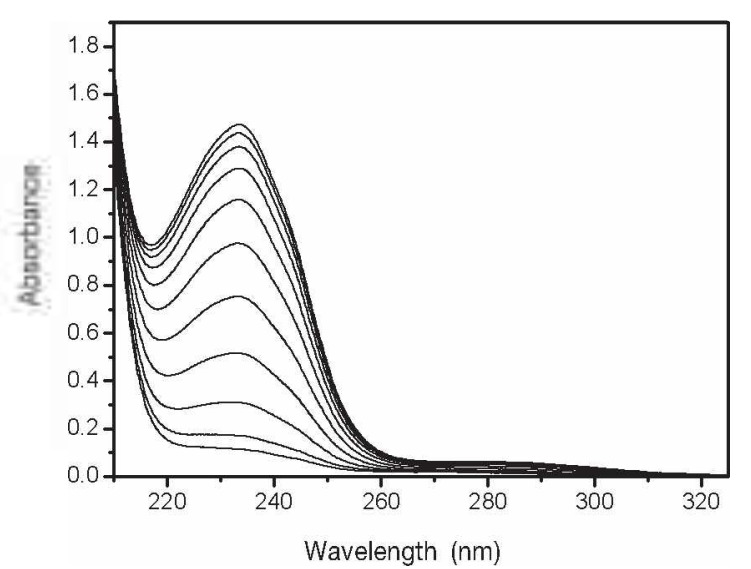

Figure 4. UV-visible spectral changes during oxidation of LA by maize LOXI. The reaction was started by adding $6 \mu \mathrm{g}$ purified maize LOXI to $50 \mathrm{mM}$ Tris- $\mathrm{HCl}(\mathrm{pH} 7.2)$ containing $0.5 \mathrm{mM} \mathrm{LA}, 0.05 \%$ Tween-20 at $25^{\circ} \mathrm{C}$ in a final volume of $2.5 \mathrm{~mL}$. Spectra were recorded at $2 \mathrm{~min}$ intervals for $22 \mathrm{~min}$ in a Shimadzu UV-2550) spectrophotometer with a resolution of $0.2 \mathrm{~mm}$.

cycle. UV-visible spectral change during the maize LOXI reaction is shown in Figure 4. HPODE was quantified by measuring absorbance at $234 \mathrm{~nm}\left(\varepsilon=25.000 \mathrm{~cm}^{-1} \mathrm{M}^{-1}\right)$, a characteristic conjugated diene signal ${ }^{25}$ Concomitant formation of oxo-octadecadienoic acid (OXOD) was estimated by measuring absorbance at $268 \mathrm{~nm}\left(\varepsilon=22,000 \mathrm{~cm}^{-1} \mathrm{M}^{-1}\right)$. The ratio of $234 \mathrm{~nm}$ to $268 \mathrm{~nm}$ absorbance indicated that the molar concentration of OXOD was approxinately $4.9 \%$ of the molar concentration of HPODE at $t=14 \mathrm{~min}$. The rate of nonenzymatic autooxidation of LA was negligible under the conditions used here. Therefore, maize LOXI produced HPODE as a major product and OXOD as a minor product. TPP-reduced reaction products were separated by SP-HPLC and unambiguously identified by GC-MS and NMR. As reported previously, ${ }^{\text {is }}$ maize LOX1 generated four major products (I, II. III. IV): these products were 13-(9Z,IIE) HPODE (I). 13-(9E, 11E)HPODE(II), 9-(10E, 12Z)HPODE(III), and $9 \cdot$ (10E, 12E)HPODE (IV).

Dependence of product distribution on reducing agents. Reaction products were reduced with TPP or $\mathrm{NaBH}_{4}$ and analyzed by SP-HPLC (Figure 5). Since OXOD is formed by delydration of HPODE and can be reduced to hydroxyoctadecadienoic acid (HODE) by $\mathrm{NaBH}_{4}$ but not by TPP. the distribution of products was expected to depend on the choice of reducing agent. As shown in Table 2. the relative proportions of 13-(9Z.11E)-HPODE and 9-(10E.12Z)-HPODE were slightly ligher when the reducing agent was $\mathrm{NaBH}_{4}$. Therefore. we conclude that maize LOXI produced 13-(9Z. 11E)-OXOD and 9-(10E,12Z)-OXOD by delydration of 13-(9Z, IIE)-HPODE and 9-(10E. 12Z)-HPODE. respectively. To avoid reduction of OXOD to HODEs and simplify product analysis. TPP was used as a reducing agent in all subsequent studies reported here. Analysis of TPP-reduced products of the LOXl reaction with LA showed that the positional specificity of maize LOXI was 13-HPODE:9-HPODE $=52.2$ : 47.8 (Table 2). This result is consistent with our previous report $^{6}$ and confinms that maize LOXI exhibits dual posi- 


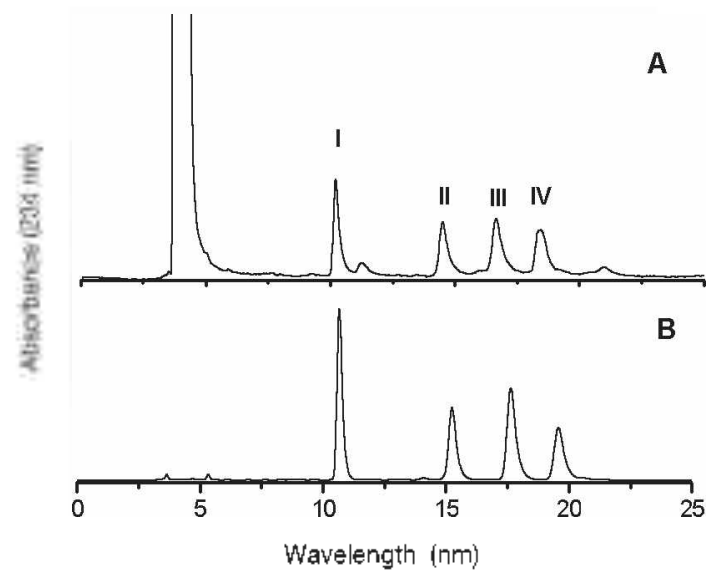

Figure 5. SP-HPLC analysis of regioisomers produced by maize LOXI. Reaction products were reduced with TPP (A) or $\mathrm{NaBH}_{4}(\mathrm{~B})$ as described in Esperimental Section, loaded on a Mightysil Si 60 column ( 250 X $4.6 \mathrm{~mm}, 5$ um particle size) from Kanto Chemical (Tokyo, Japan) and eluted with an isocratic solvent system consisting of $m$-hexane/2-propanol/acetic acid $(100 / 2 / 0.1, \mathrm{v} / \mathrm{v} / \mathrm{v})$ at a flow rate of $1.0 \mathrm{~mL} / \mathrm{min}$

Table 2. Distribution of maize LOXI reaction products reduced with TPP or $\mathrm{NaBH}_{4}$

\begin{tabular}{ccccc}
\hline \multirow{2}{*}{$\begin{array}{c}\text { Cedution } \\
\text { method }\end{array}$} & \multicolumn{4}{c}{ Conpounds } \\
& $13-(9 \mathrm{Z}, 11 \mathrm{E})-$ & $13-(9 \mathrm{E} .11 \mathrm{E})-$ & $9-(10 \mathrm{E} .12 Z)-$ & $9-(10 \mathrm{E} .12 \mathrm{E})-$ \\
& $\operatorname{HPODE}\left({ }^{\circ} \mathrm{o}\right)$ & $\operatorname{HPODE}\left({ }^{\circ} \mathrm{o}\right)$ & $\operatorname{HPODE}\left({ }^{\circ} \mathrm{o}\right)$ & $\operatorname{HPODE}\left({ }^{\circ} \mathrm{o}\right)$ \\
\hline TPP & 29.0 & 23.2 & 26.0 & 21.8 \\
$\mathrm{NaBH} 4$ & 32.9 & 20.2 & 28.9 & 18.0 \\
\hline
\end{tabular}

tional specificity with both LNA and LA.

Dependence of product distribution on sulstrate concentration. We previously proposed that the enzyme-initiated first step of the reaction involves abstraction of bis-allylic hydrogen at $\mathrm{C}-1 \mathrm{ll}$ from the substrate. followed by dissociation of the delocalized carbon-centered bis-allyllic radical intermediate, which is subsequently oxygenated outside the active site of the enzyme. ${ }^{15}$ If this is the case, the bis-allylic radical intermediate needs to be released from the maize LOX1 active site prior to the oxygenation step and kinetically-controlled products will be formed in the initial stage of the reaction. as shown in Figure 6. Thermodynamically-controlled products are also produced when the kinetically-formed peroxyl radical undergoes the bond rotation followed by $\beta$-fragmentation as shown in Figure 6. This mechanism has been proposed previously for the autooxidation of unsaturated fatty acid methyl ester. ${ }^{3}$

Formation of thermodynamically-controlled products re-

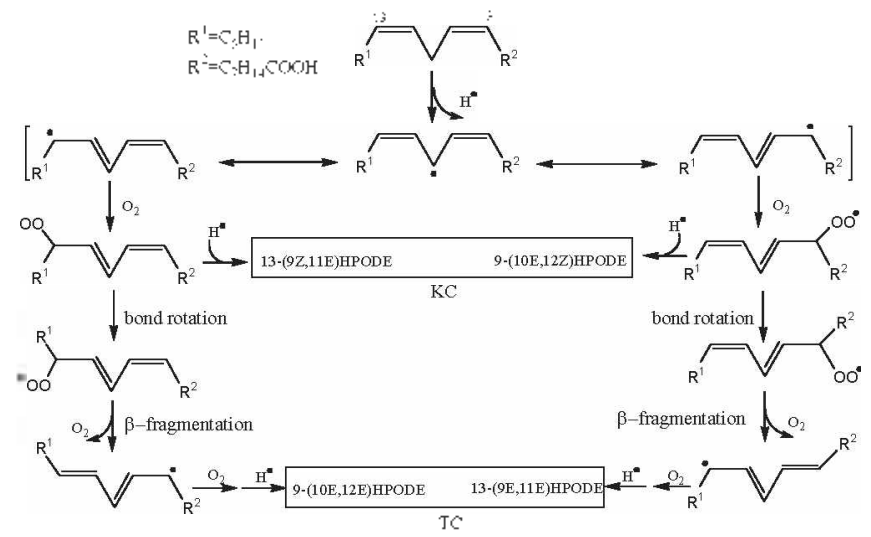

Figure 6. Mechanism for formation of kinetically-and themodynamically-controlled products by dual positional specific maize LOXI.

quires bond rotation and $\beta$-fragmentation of kinetically controlled products. Because the bis-ally lic hydrogen of LA is an efficient hydrogen atom donor and the availability of a hydrogen atom donor is critical for the proposed maize LOXI reaction mechanism. substrate concentration is predicted to be an important detenninant of reaction product distribution. Indeed, the product distribution was strongly dependent on the concentration of LA, and more importantly. kineticallycontrolled regioisomers fonmed preferentially at high substrate concentration. The enzyme concentration, however, did not influence product distribution (Table 3). These results clearly support the idea that the carbon-centered bis-allylic radical species is released from the maize LOXI active site and oxygenated outside the active site to form kinetically-controlled cis/trans isomers of HPODE, which are subsequently converted to thennodynamically-controlled products by the bond rotation followed by $\beta$-fragmentation.

Monitoring the fomation and final concentrations of HPODEs as a function of enzyme concentration. The active form of LOX contains $\mathrm{Fe}$ (III). which is thought to abstract the bis-allylic hydrogen at C-ll of LA and reduced to Fe(II) during the initiation step of enzyme catalysis. ${ }^{26}$ Consistent with this hypothesis. hydrogen abstraction by a mononuclear ferric hydroxide complex was demonstrated in a model study. "If the bis-allylic radical leaves the LOXI active site prior to oxygenation, and the enzyme will remain inactive until $\mathrm{Fe}$ (II) is reoxidized to $\mathrm{Fe}$ (III) by HPODE. This hypothesis was tested by monitoring the formation of HPODE at different enzyme concentrations. As shown in Figure 7, the final concentration of HPODE increased in an enzyme concentration-dependent manner. This indicates that a signi-

Table 3. Dependence of product distribution on the substrate concentration during maize LOXl-catalyzed oxidation of LA

\begin{tabular}{|c|c|c|c|c|c|c|c|}
\hline $\begin{array}{l}\text { Haize LOX1 } \\
\text { (yg) }\end{array}$ & $\begin{array}{l}\text { LA } \\
(\mathrm{m} .11)\end{array}$ & $\begin{array}{c}13-(9 Z, 11 \mathrm{E})-\mathrm{HPODE} \\
(0)\end{array}$ & $\begin{array}{c}9-(10 \mathrm{E}, 12 \mathrm{Z})-\mathrm{HPODE} \\
(10,1))\end{array}$ & $\begin{array}{l}\mathrm{KC} \\
(0.0)\end{array}$ & $\begin{array}{c}\text { 13-(9E.11E)-HPODE } \\
(1,(1)\end{array}$ & $\begin{array}{c}9-(10 \mathrm{E} .12 \mathrm{E})-\mathrm{HPODE} \\
\left(\begin{array}{c}(1) \\
(1)\end{array}\right.\end{array}$ & $\begin{array}{l}\text { TC } \\
\left({ }^{0} \cdot 0\right)\end{array}$ \\
\hline 72 & 0.03 & 19.7 & 19.2 & 38.9 & 21.2 & 39.9 & 61.1 \\
\hline 72 & 0.04 & 23.3 & 19.2 & 42.5 & 26.4 & 31.1 & 57.5 \\
\hline 72 & 0.05 & 26.1 & 20.3 & 46.4 & 27.9 & 25.7 & 53.6 \\
\hline 72 & 0.10 & 26.7 & 19.4 & 46.1 & 29.6 & 24.3 & 53.9 \\
\hline 72 & 0.50 & 29.0 & 26.0 & 550 & 23.2 & 21.8 & 45.0 \\
\hline 1.0 & 0.50 & 29.3 & 28.7 & 580 & 210 & 21.0 & 42.0 \\
\hline
\end{tabular}




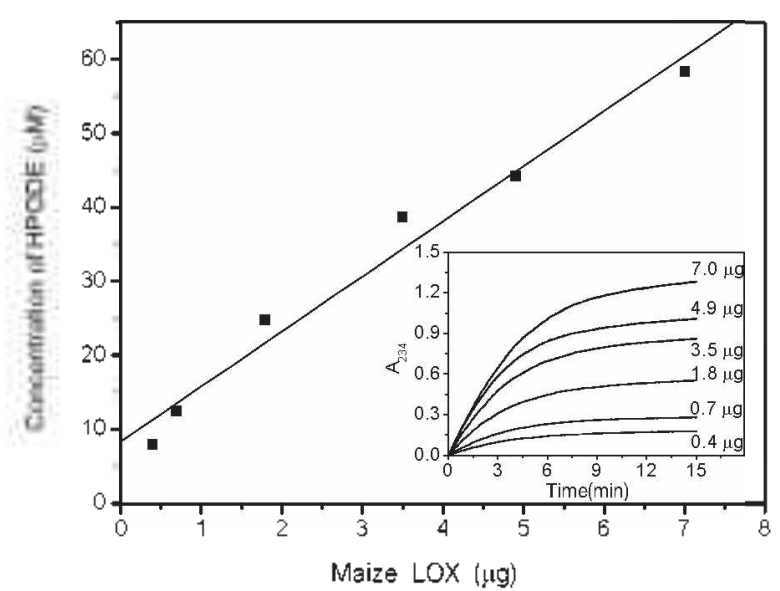

Figure 7. Monitoring the formation and final concentrations of HPODE at different concentrations of maize LOX1. HPODE was quantified in the presence of various amounts of enzyme $(0.4,0.7$, $1.8,3.5,4.9,6.0$ or $7,0 \mu \mathrm{g}$ ). The standard reaction misture contained $0.5 \mathrm{mM} \mathrm{LA}, 005 \%$ Tween 20 (v/v) and $50 \mathrm{mM}$ Tris-HCl (pH 7.2) in a tinal volume of $2.5 \mathrm{~mL}$. Reactions were monitored spectrophotometrically at $234 \mathrm{~nm}$ at $25^{\circ} \mathrm{C}$ for $15 \mathrm{~min}$. Inset shows each time course of the $\mathrm{LOX}$ reaction.

ficant fraction of the enzyme is converted into inactive form during the initiation step of catalysis. Since the formation of HPODE is rapidly saturated the inactivation is not due to a random irreversible inactivation during tumover but Figure 7 suggests HPODE is not readily available to reoxidize the inactive $\mathrm{Fe}(\mathrm{II})$ species. Therefore. enzyme kinetic data also supports the proposed enzyme-initiated reaction mechanism for maize LOXl

\section{Discussion}

Even though progress has been made in understanding the substrate specificity. access. orientation. oxygen pathway. regioselectivity. and stereoselectivity of traditional LOXs, important questions about the determinants of regio- and stereoslectivity of these enzymes still remain unanswered. ${ }^{4.7}$ To our knowledge maize LOX 1 and soybean LOX3 are only examples of completely non-stereoselective dual positional specific LOX in plants as summarized in Table 1 . It has been hypothesized that the external loop in domain III may be structurally required for positional specificity and that absence of the external loop. as in pea LOXN2. may be mechanistically responsible for dual positional specificity. However. as shown in Figure 2. a putative extemal loop in domain III is retained in maize LOXI and soybean LOX3. Therefore, deletion of the extemal loop may not be the only determinant of dual positional specificity. at least in the case of maize LOXl and soybean LOX3. On the other hand, the hydrophobic character on the molecular surface of catalytic domain in maize LOXI may play important roles in orientation of substrate binding and oxygenation of the bisallylic radical species. which are critical factors to determine regiospecificty and stereospecificity of maize LOX1. The role of hydrophobic surface of maize LOXI in the enzyme-initiated catalytic mechanism has been proposed. ${ }^{15}$
The proposed mechanism for positional specificity of traditional LOXs implies that enzyme-bound iron is required for oxygen activation and may influence the site of oxygenation. However. it is difficult to reconcile the participation of $\mathrm{Fe}$ (II) in oxygen activation with the fact that abstraction of the prochiral hydrogen by $\mathrm{Fe}(\mathrm{III})-\mathrm{OH}$ should be antarafacial to oxygen insertion. In order to explain this contradiction. Knapp and coworkers ${ }^{14}$ suggested the existence of a separate channel specifically for oxygen access. that interfaces with the active site on the face of cavity IIa (i.e. opposite Fe(II)): they also proposed that bulky hydrophobic anumo acid residues would play a critical role in controlling access of oxygen to the proposed channel. We recently proposed the existence of a segregated oxygen channel and an enzyme-initiated mechanism for dual positional specific maize LOX ${ }^{1{ }^{15}}$ In the context of this model, we propose here that the bond rotation followed by $\beta$-fragmentation, as shown in Figure 6. can explain formation of both kinetically - and thermodynamically-controlled products. This model also predicts that the availability of a hydrogen atom donor would play a critical role in determining the distribution of reaction products. If the hydrogen atom donor is readily available. 13-(9Z,11E) and $9-(10 \mathrm{E}, 12 \mathrm{Z})$ perosyl radicals will be rapidly converted to kinetically-controlled products. 13-(9Z.11E)HPODE and 9(10E, 12Z)HPODE. Otherwise. the delocalized bis-allylic radicals will undergo a bond rotation followed by $\beta$-fragmentation, leading to themodynamically-controlled products. 9-(10E, 12E)HODE and 13-(9E, 11E)HODE. Therefore, the results shown in Table 3 further supports the proposed enzymeinitiated mechanisn of dual positional specific maize LOX1 and Figure 6 provides a mechanistic rationale for the formation of both kinetically- and thennodynamically-controlled products.

Previous studies also showed that the reaction between the bis-allylic radical and triplet oxygen is diffusion-controlled in aqueous solution. ${ }^{14}$ However. oxygen concentration was an important determinant of product distribution during soy bean LOX2/LOX3-catalyzed oxidation of $\mathrm{LA}^{22}$ Because both thermody namically - and kinetically-controlled products are generated during naize LOX1-catalyzed oxidation of LA, the oxygen supply to the bis-allylic radical may be limited due to the segregation of oxygen channel and thus, the bis-allylic radical will be easily released from the active site and oxygenated non-enzymatically at the enzyme surface. This produces a racemic mixture of $\mathrm{C}-9$ or $\mathrm{C}-13$ perosyl radicals, and the peroxyl radicals are subsequently converted into kinetically-controlled products or thermodynamically-controlled products depending on the availability of a hydrogen aton donor. In addition, if the bis-allylic radical is released from the enzyme active site to be oxygenated by a non-enzymatic mechanism at the enzyme surface. the perosyl radical would not be available for reoxidation of $F e$ (II) in the active site and the enzyme will remain inactive. This is clearly demonstrated in Figure 7. Alternatively. the catalytically active yellow LOX-Fe(III) might be converted into catalytically inactive purple LOX-Fe(III) by excess HPODE. This alternative possibility, however, is not likely. because the concentration of HPODE at saturation is linearly proportional to 


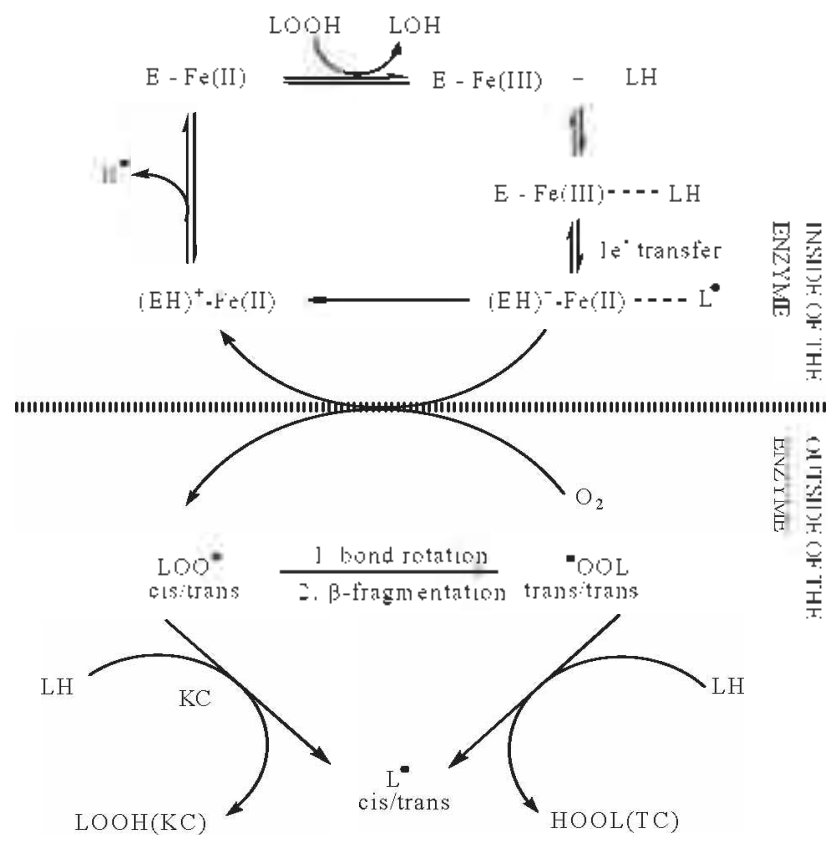

Figure 8. Substrate as a hydrogen atom donor in enzyme-initiated cataly sis of maize LOX1.

enzyme concentration. as seen in Figure 7. Therefore. the bis-allylic radical species is generated in the enzyme active site by abstraction of hydrogen at $\mathrm{C}-11$, and this resonance stabilized intermediate is subsequently released from the active site. undergoing oxy genation on the enzy me surface by a non-enzy matic mechanism.

The overall mechanism of dual positional specific maize LOX1 is summarized in Figure 8. In this mechanism, a substrate molecule serves as a hydrogen atom donor for the peroxyl radical species, and therefore. substrate availability plays a critical role in the relative abundance of kineticallyand thermodynamically-controlled reaction products. Together with previous regiochemical and stereochemical analysis. the results presented here strongly support enzyme-initiated catalysis with the bond rotation followed by $\beta$-fragmentation for dual positional specific maize LOX 1 . The regioisomers of hydroperoxy fatty acids produced by maize LOX1 are expected to exert diverse roles in plant host defense. possibly acting as signaling molecules for the biosynthesis of antifungal/antimicrobial plytooxylipins, ${ }^{29}$ and/or as precursors for the biosynthesis of cutin monomers. "Furthermore. bisallylic or corresponding peroxyl radical species are a potential source of reactive oxy'gen species (ROS). ${ }^{31}$ and thus dual positional specific maize LOX1 may be a prototype for enzymatic production of ROS during peroxidation of unsaturated fatty acids. Possible involvement of dual positional specific LOX in ROS signaling and disease resistance needs to be studied further. ${ }^{32-35}$

Acknowledgments. This work was supported by Korea Research Foundation (2007-313-F00021) and Agricultural Research Promotion Center (106074-03-2-CG000) to $O$. Han. We thank Dr. Pasqua Veronico for kindly giving us the coordinates of homology modeled structure for pea LOXN2.

\section{References}

1. Siedow, J. N. Antht. Rev Plant Physial. Plont Mol. Biol. 1991, 42,145 .

2. Brash, A. R. J. Biol. Chem 1999, 274, 23679

3. Porter, N. A.; Caldwell, S. E.; Mills, K. A. Lipids 1995, 30, 277.

4. Feussner, I.: Wastenack, C. Rev. Plant Biol. 2002, 53,275

5. Lutteke, T; Krieg, P; Furstenberger, G.; von der Lieth, C. W. Bioinfomatics 2003, 19, 2482

6. Kim, E. S.: Choi, E.: Kim, Y.: Cho, K.: Lee, A.: Shim, T.: Rahwal, R.; Agrawal G. K.; Han, O. Plant Hol. Biol. 2003, 52, 1203.

7. Hughes, R. K.: West, S. I.; Hornostaj, A. R.: Lawson, D. M.; Fairhurst, S. A.; Sanchez, R. O.; Hough, P.; Robinson, B. H.; Casev, R. Biochem. J. 2001, 353,345.

8. Fuller, M. A.; Weichert, H.: Fischer, A. M.: Feussner, I.: Grimes, H. D. Awh. Biochem. Biophys. 2001, 388, 146.

9. Garbe, L.; Almeida, R. B.: Nagel, R.: Wackerballer, K.; Tressl, R. J.Agric. Food Chem. 2006, 54, 946

10. Kim, E. S.; Kim, H.; Park, R.; Lee, Y; Han, O. J. Plan Physiol. $2002,159,1263$.

11. Nemchenko, A.; Kunze, S.; Feussner, I.; Kolomiets, M. I. E.tp. Bot. 2006, 57, 3767 .

12. Cho, K, Jang, S.: Huon, T.: Park, S.: Han, O. J. Biochem. Mol. Biol. 2007, $40,100$.

13. Butovich, I. A.; Reddy, C. C. Biochim Biophss Acta 2001 , $15+6,379$.

14. Knapp, M. I.; Seebeck, F. P; Klinman, J. P. J. Am Chem Soc. 2001. 123.2931

15. Jang, S.; Huon, T.; Kim, K.; Um, E; Han, O. Org. Lett. 2007, 9, $\$ 113$.

16. Veronico, P.; Giannino, D.; Melillo, M. T; Leone, A.; Reyes, A.; Kennedy, M. W. Bleve-Zacheo. T. Plant Phusiol 2006, 141 . 1045 .

17. Coffa, G.; Imber, A. N.; Maguire, B. C.: La.mikanthan, G.; Schneider, C.; Gaftiney, B. I.; Brash, A. R. J. Biol. Chem. 2005. 280,38756 .

18. Zhang, L.; Hamberg, M. Lipids 1996, 31,803.

19. Wang, R.: Shen, W.: Lilu, L.; Jiang, L.; Lill, Y.: Su, N.; Wan, T. Plont Mol. Biol. 2008, 66, 401

20. Fenssner, I:; Bachmann, A.: Hohne, M.: Kindl, H. FEBS Letr. $1998,+31,433$

21. Hughes, R. K.; Wu, Z; Robinson, D. S.; Hardy, D.; West, S. I.; Fairhurst, S. A.: Casey, R. Biochem. J. 1998, 333, 33.

22. Fukushige, $H_{\text {; }}$, Wang, $C$.; Simpson, T. D.: Gardner, H. W. Hildebrand, D. F. J. igric. Food Chem 2005, 53, 5691.

23. Tomchick, D. R.; Phan, P; Crmborowshi, M.; Minor, W: Holman, T. R. Biochentistry 2001, $40,7509$.

24. Laskowski, R. A; Rulluanmn, I. A.: MacArthur, M. W: Kaptein, R.; Thomton, J. M. J. Biomol. MIR 1996, 8, 477.

25. Hilbers, M. P.; Finazzi-Agro, A.; Veldink, G. A.; Vliegenthart, I. F. G. htt. J. Biochem. Cell Biol 1996, 28,751.

26. Schilstra, M. J.; Veldirk, G. A.; Vliegenthart, I. F. G. Biochemistry 1994,33, 3974.

27. Goldsmith, C. R.; Stack, T. D. P. Mory. Chent 2006, 45, 6048

28. Kulu, H. Prostaglandins Other Lipid Mediat. 2000, 62, 255

29. Blee, E. Fent Lipid 1998, 100, 121

30. Pinot, F.; Benveniste, I.; Salaun, J. P.; Loreu, O.; Noel, T. P.; Schreiber, L.: Durst. F. Biochem. J. 1999, 342,27

31. Bhattacharjee, S. Cur Sci. 2005, 89, 1113.

32. Lee, S. H.: Ahn, S. J.: Im, Y. J.: Cho, K.; Chung, G. C.; Cho, B. H.: Han, O. Biochem Biophus Res. Commm 2005, $330,1194$.

33. Cho, K; Agrawal, G. K.; Shibato, T; Tung, Y. H.; Kim, Y. K.; Nalum, B. H.: Iwa, N. S.: Tamogami, S.: Han, O:; Kohda, K.; Iwahashi, H.; Rakwal, R. J. Proteome Res. 2007, 6, 3581

34. Kim, I. Y.; Park, S. T.; Jang, B.: Tung, C. H.: Ahn, S. T.; Goh, C. H.: Cho, K: Han, O.: Kang. H. Plant J. 2007, 50, 439.

35. Mita, G; Fasano, P; De Domenico, S.; Perrone, G.; Epifani, F; Iannacone, R.; Casey, R.: Santino, A. J. Exp. Bot. 2007, 58 , 1803. 